NACIONAL

\title{
Trabajo penitenciario: Análisis en virtud del derecho de igualdad ante la ley
}

Prison labor: Study of the principle of equality before the law

\author{
Javiera Farías Pereira \\ Leasur, Chile \\ Agustín Walker Martínez \\ Leasur, Chile
}

RESUMEN El artículo describe la regulación establecida en el Código del Trabajo en materia de remuneraciones y su protección, y la contrasta con la contenida en el Decreto 943, que establece un estatuto laboral y de formación para el trabajo penitenciario aplicable a los trabajadores que desarrollan sus funciones privados de libertad, bajo un vínculo de subordinación y dependencia con su empleador. Con ello se busca graficar la situación de desigualdad normativa en que se encuentran los trabajadores privados de libertad en relación con sus pares en el exterior, con la consecuente vulneración del derecho de igualdad ante la ley, a la luz de las normas constitucionales y del derecho internacional de los derechos humanos.

PALABRAS CLAVE Trabajo penitenciario, privación de libertad, cárcel.

ABSTRACT The article describes the Labor Code salary's protection and regulation, and compares it with the Decree 943 that contains a labor and training statute for prison labor. The comparison is made with the purpose of showing the inequality of both regimes, to the detriment of the workers deprived of freedom, and the human right violations (from both constitutional and international human rights law) produced by this inequality.

KEYWORDS Labor prison, deprivation of liberty, jail. 


\section{El trabajo penitenciario en Chile}

Pese a que la realidad carcelaria es un asunto que normalmente permanece invisibilizado y ajeno al escrutinio de la opinión pública, el trabajo penitenciario suele destacar dentro de este contexto, principalmente por su relevancia en el proceso de reinserción social.

En Chile, de acuerdo con cifras de Gendarmería del año 2016, un total de 42.702 personas se encontraban privadas de libertad, $31 \%$ en prisión preventiva y $69 \%$ condenadas, ${ }^{1} \mathrm{y}$ dentro de este último grupo, el $50 \%$ accedió a actividades laborales, es decir, 14.851 personas. De ellas, 6.990 desarrollaban labores de artesanos informales, 4.420 hacían servicios de mantención, 1.236 se encontraban en Centros de Educación y Trabajo, 1.021 eran independientes con oficios, 814 eran personas con trabajo al interior de las unidades penales y 170 laboraban fuera de ellas. ${ }^{2}$

En la actualidad, esta materia se encuentra regulada casi en su totalidad en el Decreto 943, vigente desde el año 2011, que establece un estatuto laboral y de formación para el trabajo penitenciario. Este instrumento reglamenta principalmente tres formas de trabajo: la actividad laboral penitenciaria, que corresponde a las labores desempeñadas para un empleador o empresa regulada por el Código del Trabajo; la prestación de servicios de internos, que consiste en la actividad laboral en virtud de un contrato civil, y la formación para el trabajo. Dentro de esta última categoría se encuentran las actividades de apoyo a las necesidades de los recintos penitenciarios, el entrenamiento ocupacional o terapéutico y las tareas desarrolladas en los Centros de Educación y Trabajo.

Pese a que son muchas las perspectivas desde las cuales es posible abordar la regulación e implementación del trabajo penitenciario en Chile, aquí nos centraremos en la situación de las personas privadas de libertad que desarrollan esta actividad en virtud de un contrato de trabajo. Este grupo, aunque minoritario, al estar sujeto a la misma regulación que los trabajadores en el medio libre es el que mejor representa la situación de profunda desigualdad en que se encuentran las personas intramuros respecto de sus pares en el exterior, principalmente en cuanto a las remuneraciones que perciben y a la protección de las mismas.

Con este fin, examinaremos las normas sobre sueldo mínimo y descuentos a las remuneraciones contenidas en el Decreto 943, para luego contrastarlas con las disposiciones que en la materia establece el Código del Trabajo. Posteriormente, esta normativa se analizará en virtud de los estándares nacionales e internacionales relativos al trabajo penitenciario y al derecho de igualdad ante la ley.

1. Dirección Nacional de Gendarmería de Chile, «Boletín estadístico 2», febrero de 2017, p. 3, disponible en http://bit.ly/2FMzO $7 \mathrm{~L}$.

2. «Boletín estadístico 2», p. 6. 


\section{Regulación del trabajo penitenciario}

El Decreto 943 establece determinados principios que deben inspirar el trabajo en la cárcel. En primer lugar, se indica que todas las personas podrán acceder a él con independencia de su situación procesal, que éste será siempre voluntario y que no podrá utilizarse como castigo ni como fuente de lucro para la administración. Se declara también la existencia de una relación de derecho público entre el Estado y quien se encuentre privado de libertad, y un deber de promoción por parte de Gendarmería consistente en generar condiciones que mejoren el acceso al trabajo y favorezcan la integración laboral, reconociendo la diversidad de quienes habitan los recintos penitenciarios. Por último, se establece que toda actividad productiva deberá ser remunerada y se instituye la obligación de estimular el ahorro de internos e internas.

Con respecto al trabajo que se ejecute en virtud de la legislación laboral común, se consagra la total aplicación de la misma, tolerando ciertas las restricciones cuando éstas se funden en el resguardo del régimen penitenciario, como las aplicadas al derecho a sindicalización, a huelga, y a negociar colectivamente (Decreto 943, artículo 4).

En el título 3, que regula las actividades ejercidas en virtud de un contrato de trabajo, se reitera que todos los aspectos de la relación laboral se regirán por las exigencias técnicas y las normas aplicables al trabajo en libertad. Al referirse a la remuneración, la normativa señala que se asegurará una retribución «conforme al rendimiento, categoría laboral y clase de actividad desempeñada» (artículo 21). Esto se complementa con lo dispuesto en el artículo 43, que indica que la remuneración será idéntica a la de los trabajadores libres que desempeñen la misma labor.

No obstante, en relación con la consagración práctica de estos principios, llama la atención que el reglamento en ningún momento declare expresamente el derecho de los trabajadores a recibir el sueldo mínimo fijado por ley.

Pero la particularidad más relevante que se observa para efectos del presente trabajo es la existencia de diversas deducciones a las remuneraciones, consagradas en el artículo 47 del decreto - en sintonía con lo dispuesto en el artículo 88 del Código Penal-, adicionales a las ya establecidas en la normativa laboral común. Entre ellas se encuentran: i) $11 \%$ para hacer efectiva la responsabilidad civil proveniente del delito cuando la sentencia judicial la establezca; ii) hasta $5 \%$ destinado a indemnizar los gastos que la actividad laboral ocasione al establecimiento; y iii) 15\% destinado a la formación de un fondo individual de reserva.

\section{El contraste con la regulación contenida en el Código del Trabajo}

El artículo 42 del Código del Trabajo, al referirse a los elementos que componen la remuneración, menciona en primer lugar el sueldo, indicando que éste no podrá ser inferior a un ingreso mínimo mensual. Con esto se pretende asegurar a los trabajado- 
res una contraprestación por su labor que permita la satisfacción de sus necesidades, sin importar la actividad que ejecuten, cuyo valor se estima en relación con cuánto le costaría cubrir dicho costo (Humeres Noguera, 2009: 224).

Considerando que el Decreto 943 no contiene normas que se refieran al salario mínimo y que en él se establece la plena aplicación del Código del Trabajo a los trabajadores privados de libertad, se debe entender que esta garantía resulta a su respecto plenamente aplicable.

Sin embargo, la ausencia de una regulación expresa de este derecho debilita su exigibilidad. Así, esta omisión, en conjunto con la declaración que autoriza la limitación de determinados derechos laborales en función del mantenimiento del régimen penitenciario, podría servir de fundamento jurídico para su restricción o incumplimiento.

Por otra parte, el artículo 57 del Código del Trabajo establece, como regla general, que las remuneraciones y las cotizaciones de seguridad social son inembargables. Se exceptúan de esta norma los casos en que éstas asciendan a un monto superior a 56 UF, pues en dicha situación será embargable el monto que exceda aquella cifra. Otro escenario especial se da cuando el trabajador adeuda pensiones alimenticias debidas por ley y establecidas judicialmente; cuando comete defraudaciones, hurto o robo contra los bienes del empleador y en ejercicio de su cargo; o bien cuando adeuda remuneraciones a persona que le prestaron servicios en calidad de trabajador. En todos estos casos, se autoriza a embargar hasta el 50\%.

Como se ve, la legislación laboral consagra una robusta protección a las remuneraciones por la vía de la inembargabilidad. Así, se autoriza su embargo solo en casos excepcionales - establecidos en el Código del Trabajo o en otras leyes- y hasta un monto determinado. Tratándose de la comisión de delitos, solo se autoriza en tres circunstancias y únicamente cuando se cometen en el marco de la relación laboral.

Este contexto difiere totalmente de aquél en que se encuentran las personas privadas de libertad, en el que los créditos que se originan en la responsabilidad civil derivada del delito no necesitan ser cobrados en un juicio ejecutivo ni en virtud una autorización judicial que autorice el embargo, sino que la deuda se descontará automáticamente de la remuneración. Cabe destacar que, atendido el bajo ingreso que reciben las personas privadas de libertad, si en estos casos se siguiera lo dispuesto en el artículo 57 del Código del Trabajo - en cuanto a que las remuneraciones solo pueden embargarse sobre el monto que supere las 56 UF- éstas serían, en la práctica, inembargables.

En relación con los descuentos a las remuneraciones, el artículo 58 del Código del Trabajo distingue entre aquéllos que el empleador está obligado a realizar y los autorizados por el trabajador. Entre los primeros se encuentran los impuestos, las cotizaciones de seguridad social, las cuotas sindicales y las obligaciones con instituciones de previsión u organismos públicos. Todos los demás descuentos deberán contar con la autorización escrita del trabajador. 
A su vez, en relación con los descuentos no obligatorios, la ley establece una regulación especial para aquéllos autorizados por el trabajador y que estén destinados a la adquisición de una vivienda, o a la educación del trabajador, su cónyuge, conviviente civil o hijos. En estos casos se autoriza al empleador a otorgar mutuos o créditos sin interés al trabajador, en virtud de los cuales podrá descontar mensualmente hasta el $30 \%$ de la remuneración.

Tratándose de descuentos para el pago de cualquier otra obligación, la cantidad máxima que se podrá deducir será del $15 \%$. A su vez, se indica que en ningún caso el total de las deducciones podrá ser superior al $45 \%$ de la remuneración total.

Todo lo anterior contrasta radicalmente con la situación que enfrentan quienes trabajan privados de libertad, puesto que respecto de su remuneración no existe un porcentaje máximo para los descuentos ni tampoco se les otorga la facultad de aceptarlos o rechazarlos.

Por otra parte, la normativa laboral prohíbe expresamente que el empleador deduzca, retenga o compense sumas por arriendo de habitación, luz, uso de herramientas, entrega de agua, medicinas, atención médica u otras prestaciones en especie. Esta norma se opone drásticamente a la regulación contenida en el reglamento, la que obliga al trabajador a asumir los costos que implica la ejecución de su trabajo, los cuales de acuerdo con la normativa laboral deben ser de cargo del empleador.

\section{Vulneración de la garantía constitucional de igualdad ante la ley}

Los contrastes antes descritos generan una diferencia sustancial entre las personas que trabajan en el medio libre y quienes lo hacen en recintos penitenciarios. Esta situación es cuestionable desde el punto de vista de la normativa constitucional chilena $\mathrm{y}$ desde las normas internacionales que regulan la materia.

Las letras a) y b) del artículo 47 establecen dos descuentos a las remuneraciones de las personas privadas de libertad: $11 \%$ para hacer efectiva la responsabilidad civil derivada del delito y $5 \%$ destinado a indemnizar los gastos generados al establecimiento. Esto infringe directamente el derecho a la igualdad ante la ley, en los términos del artículo 19 numeral 2 de la Constitución, ${ }^{3}$ en cuanto constituye una discriminación arbitraria ${ }^{4}$ en perjuicio de las personas privadas de libertad, añadiendo cargas monetarias, a modo de descuentos, diferentes a las establecidas para los trabajadores bajo la

3. Garantía fundamental que adquiere especial relevancia en relación con la privación de libertad: «Esta norma (el artículo 19 numeral 2) adquiere importancia si consideramos [...] que la forma de entender la sujeción especial en la que se hallan las personas privadas de libertad frente al Estado ha implicado desatender los derechos fundamentales de éstos, en contravención al deber general del Estado de garantizar los derechos en forma igualitaria a todas las personas» (Nash Rojas, 2013: 95).

4. Sentencia del Tribunal Constitucional, rol 986-07-INA, 30 de enero de 2008, considerando trigésimo. 
legislación laboral común, sin que exista una justificación plausible y jurídicamente válida para hacerlo. Tampoco resulta justificable que no se consagre expresamente el derecho de los trabajadores privados de libertad a recibir una remuneración mínima.

En términos generales, estamos frente a una vulneración a la igualdad ante la ley cuando el legislador dispone un tratamiento diferenciado, sin que exista una fundamentación razonable - en términos de la finalidad de la disposición- que justifique la limitación de este derecho. Así, «para poder determinar si se infringe la igualdad ante la ley, es necesario atender además a la finalidad perseguida por el legislador para intervenir el derecho fundamental de que se trata, la que debe ser adecuada, necesaria y tolerable para el destinatario de la misma».5

Como veremos, las diferencias establecidas en el artículo 47 letras a) y b) no son adecuadas, pues tensionan directamente con la relación de derecho público que rige la relación entre la administración y la persona privada de libertad, y no son necesarias, pues la indemnización civil puede perseguirse por las reglas generales y los costos derivados del trabajo son absorbidos por el empresario conforme al artículo 33 del Decreto 943. Tampoco resulta adecuado suprimir el derecho al sueldo mínimo fijado por la ley, pues éste se establece en función de la persona y el trabajo que efectúa - resguardando la dignidad del mismo- y no a su situación procesal; por lo mismo, tampoco resulta necesario porque no existe justificación económica que fundamente esta diferencia, ya que incluso si se asumiera que el trabajo intramuros pudiera generar un costo adicional para el empleador, éste se ve ampliamente compensado por el hecho de tener a sus trabajadores totalmente disponibles y bajo un régimen penitenciario controlado por el órgano estatal que le asegura la disciplina y orden para alcanzar un máximo rendimiento. Por último, ninguna de estas circunstancias es tolerable, pues afectan a quienes se encuentran en una situación económicamente desventajosa, marginados de la sociedad. Por tanto, carecen de una finalidad que la justifique, por lo que es una diferencia arbitraria y vulneradora de derechos fundamentales.

Tal como dispone el artículo 2 del Reglamento de Establecimientos Penitenciarios, y como lo ratifica el artículo 2 del Decreto 943, la persona privada de libertad se encuentra en una relación de derecho público con el Estado, de manera que fuera de las limitaciones a su libertad ambulatoria, «su condición jurídica es idéntica a la de los ciudadanos libres». En ese marco, las únicas restricciones oponibles a las personas privadas de libertad en su desempeño laboral son las tendientes a asegurar su custodia y seguridad, por lo que no está el Estado jurídicamente legitimado para interferir en otras esferas de la vida de esa persona. Pero, además, dicha relación de derecho público no solo es un límite al actuar del Estado, sino que también «exige a

5. Sentencia del Tribunal Constitucional, rol 1133-08-INA, 18 de noviembre de 2008, considerando decimoséptimo. 
los Estados [...] adoptar medidas especiales para estas personas, permitiéndoles gozar efectivamente de aquellos derechos humanos no restringidos por la privación de libertad» (Nash Rojas, 2013: 24), lo que aplica no solo sobre los funcionarios en contacto directo con las personas privadas de libertad, sino sobre toda faceta del Estado: judicial, administrativa o legislativa (Nash Rojas, 2013: 26).

Por tanto, no solo no hay razones para efectuar los ya mencionados descuentos ni para omitir la consagración del derecho al sueldo mínimo, sino que, además, al hacerlo, el Estado infringe su deber positivo de velar por el cumplimiento irrestricto de la garantía fundamental de igualdad ante la ley en el ámbito laboral, ya que no es posible considerar la privación de libertad como un hecho suficientemente válido para el establecimiento, a nivel normativo, de cargas adicionales en la remuneración o de una eliminación de los derechos garantizados del resto de los trabajadores, pues la calidad de privado de libertad se establece «no para conceder espacios de discrecionalidad y posibilidad de abusos a la administración, sino para incorporar un lenguaje de derechos del condenado, de límites y resguardos que deben desarrollarse para contener de forma razonable los riesgos que se materializan en la prisión» (Castro, Cillero y Mera, 2010: 30).

En cuanto al descuento del $11 \%$ tendiente a hacer efectiva la responsabilidad civil derivada de la comisión del ilícito, en los hechos esto implica mermar la capacidad económica de las personas privadas de libertad —en sí misma disminuida-, que refleja más bien una profundización del castigo antes que una eficiente herramienta para hacer efectiva dicha responsabilidad. La ya mencionada relación de derecho público que caracteriza el nexo entre el Estado y la persona privada de libertad impide aceptar medidas como ésta, por medio de las cuales se restringen derechos en ámbitos distintos a los necesarios para la seguridad y custodia.

Respecto de este descuento, y siguiendo la caracterización del principio de no discriminación propuesta por la doctrina (Saba, 2007: 193-194), la vulneración de la igualdad puede ser entendida de dos maneras: primero, como discriminación, que consiste en acciones o decisiones diferenciadoras que no logran superar un test de razonabilidad sea funcional o instrumental, es decir, que no logran dar cuenta de una situación fáctica significativa que justifique la existencia de medidas desiguales. La otra forma de entender la violación de la igualdad es el sometimiento, en el que las diferenciaciones efectuadas por la autoridad constituirán categorías sospechosas de infracción a la garantía constitucional de no discriminación, en la medida en que se aplican a un grupo marginado socialmente. Hoy, en Chile y en América Latina, la población privada de libertad es, sin lugar a duda, un grupo paradigmáticamente excluido de las lógicas sociales comunes y de sus beneficios (Castro, Cillero y Mera, 2010: 198). En ese contexto, la medida de descontar $11 \%$ a quienes se encuentran en una situación fácticamente análoga —en términos laborales-a la población del medio libre es, por un lado, una acción diferenciadora que no logra demostrar una ra- 
zonabilidad en su diferenciación, ${ }^{6}$ y que, al mismo tiempo, recae sobre una población paradigmáticamente marginada de la sociedad chilena, lo que constituye una «categoría sospechosa» imposible de soslayar al momento de analizar la conveniencia de la diferencia.

En relación al descuento establecido en la letra b) del artículo 47 del Decreto 943, relativo al 5\% destinado a «indemnizar los gastos que ocasionen al establecimiento», se produce una nueva infracción al principio de no discriminación arbitraria. Este descuento es una mera arbitrariedad que no tiene otro propósito que la profundización del castigo, y la vulneración de la relación de derecho público que caracteriza -o debiera caracterizar- la relación del Estado con la persona privada de libertad, por dos razones: primero, porque todo costo básico derivado del trabajo efectuado por las personas privadas de libertad es absorbido por el empresario, conforme al artículo 33 del Decreto 943, por lo que el supuesto detrimento económico causado a la administración penitenciaria ya es saldado, en cuanto dicha norma obliga al empresario a pagar a Gendarmería el consumo de los servicios básicos de los que haga uso (agua, energía, gas, teléfono, extracción de basura y otros); segundo, por aplicación del principio de normalización o laboralización (Reglas Mínimas para el Tratamiento de los Reclusos, regla 72), conforme al cual el trabajo penitenciario debe asimilarse lo más posible al trabajo del medio libre.

Aplicando este principio, quienes trabajen con contrato laboral en el medio libre no deben por regla general indemnizar al establecimiento en el que trabajan o donde residen por percibir una remuneración. Esto es aún más absurdo desde el objetivo de reinserción social que el artículo 1 del Reglamento de Establecimientos Penitenciarios encomienda a la administración penitenciaria, pues se impone una carga adicional a la persona privada de libertad que decida y pueda trabajar, lo cual genera fuertes desincentivos y profundiza la idea de que no solo se restringe la libertad de la persona, sino que se la somete a administración de manera absoluta.

En suma, el artículo 19 numeral 2, junto con la relación de derecho público que rige la relación entre la administración penitenciaria y la persona privada de libertad, crean a nivel de legislación nacional un estándar exigible al Estado en base al cual se proscribe toda discriminación arbitraria en la regulación del trabajo penitenciario, estableciendo con suma claridad que las condiciones jurídicas en las que éste debe efectuarse deben ser iguales a las de los trabajadores del medio libre, pudiendo solo existir diferencias en aquello que se relacione con la limitación de la libertad ambulatoria. Las letras a) y b) del Artículo 47) del Decreto 943 no son medidas que digan relación con la limitación a la libertad misma y, por tanto, son diferencias injustificadas y vulneradoras de derechos fundamentales.

6. Sentencia del Tribunal Constitucional, rol 986-07-INA, considerando trigésimo. 


\section{Estándares internacionales aplicables}

La antes descrita situación no solo afecta un estándar normativo nacional, sino que se alejan de técnicas legislativas comparadas como las existentes en España (artículos 26 y 33.1 de la LOGPE) o México (artículo 93 de la LNEP), en que se consagra la igualdad en materia laboral; más importante aún, se encuentran en franca tensión con normas internacionales relativas al trabajo penitenciario y con sentencias de la Corte Interamericana de Derechos Humanos.

En relación con las normas de instrumentos internacionales en la materia, se configura claramente un estándar exigible al Estado en favor del establecimiento de normas que respeten irrestrictamente el principio de igualdad, y específicamente el principio de normalización laboral. Así, resultan aplicables, entre otras, las siguientes normas:

- Artículo 23 de la Declaración Universal de Derechos Humanos: Establece un piso mínimo para todo tipo de trabajo, incluyendo, lógicamente, el trabajo penitenciario. Consagra el derecho a que el trabajo se desarrolle en condiciones equitativas y satisfactorias, y que le asegure una existencia conforme a la dignidad humana. Prohíbe, por tanto, que se discrimine a un grupo de trabajadores respecto de otros.

- Principios y Buenas Prácticas sobre la Protección de las Personas Privadas de Libertad en las Américas (OEA): Se infringe su principio 2, que consagra el derecho a ejercer todo derecho, a excepción de aquéllos derivados de la privación temporal de libertad, y el principio 14, que establece el derecho a un trabajo efectivo, con remuneraciones equitativas y con un objetivo de reinserción social, estableciendo que el trabajo no es un medio de castigo. Por tanto, el establecimiento de cargas diferentes, sin fundamento claro, transgrede este estándar internacional.

- Regla 72 de las Reglas Mínimas para el Tratamiento de los Reclusos: Como ya se señaló, esta regla establece el llamado principio de laboralización, conforme el cual el trabajo penitenciario debe asimilarse lo más posible al trabajo común del medio libre. El no consagrar el derecho a una remuneración mínima y descontar 16\% de las remuneraciones de manera injustificada es una distinción significativa con las normas laborales comunes, con lo que se rompe el principio de laboralización en desmedro, una vez más, de las personas privadas de libertad.

- El principio 8 de los Principios Básicos para el Tratamiento de los Reclusos dispone que la administración penitenciaria debe crear las condiciones para que las personas privadas de libertad ejerzan actividades laborales, lo que se com- 
plementa con el principio 5, que dispone que las personas privadas de libertad gozan de todos los derechos fundamentales consagrados en la normativa institucional, pudiendo solo restringírseles los derechos naturalmente limitados por la privación de libertad. En ese sentido, gozan de los mismos derechos en el ejercicio de su trabajo que las personas que trabajan en el medio libre, sin poder imponérseles cargas injustificadas.

- Aun cuando no es directamente aplicable en Chile, la regla 105.3 de las Reglas Penitenciarias Europeas, exige (no faculta) a los Estados que las condiciones laborales penitenciarias se ajusten a las normas laborales del medio libre, con lo que establece un criterio general, en el sentido de que es inadmisible establecer diferencias entre las condiciones laborales de los trabajadores por el solo hecho de estar algunos privados de libertad.

A mayor abundamiento, ha sido la propia Corte Interamericana de Derechos Humanos la que ha establecido el deber positivo de los Estados de contar con una regulación penitenciaria que respete y garantice el debido goce de los derechos fundamentales no afectados por la restricción a la libertad personal. Así, en un sentido más bien general, la Corte estableció en el caso Raxcaco Reyes con Guatemala que, «como responsable de los establecimientos de detención, el Estado debe garantizar a los reclusos la existencia de condiciones que dejen a salvo sus derechos» (citado en Nash Rojas, 2013: 22).

En términos más específicos, la Corte ha señalado con suma claridad que la posición de garante del Estado le impone, respecto de las personas privadas de libertad, un deber positivo de actuación, regulación y garantía de derechos que no le es posible omitir ni mucho menos contravenir, que es lo que se produce con la regulación vigente en nuestro país. Así, la Corte en el caso Instituto de Reeducación del Menor con Paraguay, ${ }^{8}$ sostuvo:

Frente a las personas privadas de libertad, el Estado se encuentra en una posición especial de garante, toda vez que las autoridades penitenciarias ejercen un fuerte control o dominio sobre las personas que se encuentran sujetas a su custodia. De este modo, se produce una relación e interacción especial de sujeción entre la perso-

7. En el mismo sentido, sentencia del caso Fermín Ramírez con Guatemala, Corte Interamericana de Derechos Humanos, serie C núm. 126, 20 de junio de 2005, fondo, reparaciones y costas, párrafo 118; sentencia del caso Caesar con Trinidad y Tobago, Corte Interamericana de Derechos Humanos, serie C núm. 123, 11 de marzo de 2005, fondo, reparaciones y costas, párrafo 96; entre otros.

8. En el mismo sentido, sentencia del caso Pacheco Teruel y otros con Honduras, Corte Interamericana de Derechos Humanos, serie C núm. 206, 27 de abril de 2012, excepciones preliminares, fondo, reparaciones y costas, párrafos 63 y 64; sentencia del caso Yvone Neptune con Haití, Corte Interamericana de Derechos Humanos, serie C núm. 180, 6 de mayo de 2008, fondo, reparaciones y costas, párrafo 130; entre otros. 
na privada de libertad y el Estado, caracterizada por la particular intensidad con que el Estado puede regular sus derechos y obligaciones y por las circunstancias propias del encierro, en donde al recluso se le impide satisfacer por cuenta propia una serie de necesidades básicas que son esenciales para el desarrollo de una vida digna.

Ante esta relación e interacción especial de sujeción entre el interno y el Estado, este último debe asumir una serie de responsabilidades particulares y tomar diversas iniciativas especiales para garantizar a los reclusos las condiciones necesarias para desarrollar una vida digna y contribuir al goce efectivo de aquellos derechos que bajo ninguna circunstancia pueden restringirse o de aquéllos cuya restricción no deriva necesariamente de la privación de libertad y que, por tanto, no es permisible. De no ser así, ello implicaría que la privación de libertad despoja a la persona de su titularidad respecto de todos los derechos humanos, lo que no es posible aceptar (citado en Nash Rojas, 2013: 25).

De esta manera, tanto la normativa internacional como las sentencias de la Corte han sido enfáticas y consistentes en sostener un estándar de actuación exigible al Estado, en que éste, como consecuencia del principio de igualdad, de su calidad de garante, no puede, bajo ningún pretexto, dictar normas - menos aún reglamentarias- que impliquen una restricción ilegítima de derechos no afectados por la privación a la libertad personal, estableciendo discriminaciones arbitrarias en contra de la población penal.

\section{Conclusiones}

Del contraste entre la regulación aplicable a los trabajadores privados de libertad sujetos a un contrato de trabajo y a aquéllos que se desempeñan en el medio libre, es posible establecer fuertes diferencias, especialmente en lo que dice relación con la determinación del sueldo mínimo y la protección a las remuneraciones.

En base a ello, es posible sostener que las disposiciones del Decreto 943 en esta materia y lo establecido artículo 88 del Código Penal generan una discriminación arbitraria entre estas categorías de trabajadores, que contraría el estándar de conducta exigible al Estado en función del artículo 19 numeral 2 de la Constitución Política de la República, en relación con la relación de derecho público que rige el vínculo de la Administración con la persona privada de libertad. Junto con ello, constituyen también discriminaciones arbitrarias que son contrarias a normas internacionales y a los parámetros que la Corte Interamericana de Derechos Humanos ha establecido como obligación de los Estados.

En ese marco, resulta urgente ajustar la normativa a dichos parámetros y consagrar sin matices el principio de igualdad en materia laboral. Sin embargo, creemos que este ajuste no debe hacerse de cualquier manera, sino que ha de incorporar una revisión sistemática de la regulación sobre cumplimiento de las sanciones penales en 
nuestro país - especialmente las privativas de libertad-y la múltiple vulneración de derechos que en este contexto se genera. Esta labor debe decantar en la creación de una regulación - de carácter legal y no meramente reglamentario- que considere cada uno de los aspectos involucrados, es decir, en la dictación de una ley de ejecución penitenciaria.

\section{Referencias}

Castro, Álvaro, Miguel Cillero y Jorge Mera (2010). Derechos fundamentales de los privados de libertad: Guía práctica con los estándares internacionales en la materia. Santiago: Universidad Diego Portales.

Humeres Noguera, Héctor (2009). Derecho del trabajo y de la seguridad social. Tomo 1. Santiago: Jurídica de Chile.

Nash Rojas, Claudio (2013). Personas privadas de libertad y medidas disciplinarias en Chile: Análisis y propuestas desde una perspectiva de derechos humanos. Santiago: Centro de Derechos Humanos de la Facultad de Derecho de la Universidad de Chile.

SABA, Roberto (2007). «(Des)igualdad estructural». En Marcelo Alegre y Roberto Gargarella (coordinadores), El derecho de igualdad: Aportes para un constitucionalismo igualitario. Buenos Aires: Lexis Nexis.

\section{Sobre los autores}

Javiera Farías Pereira es abogada. Licenciada en Ciencias Jurídicas y Sociales de la Universidad de Chile, diplomada en Teoría de Género, Desarrollo y Políticas Públicas por el Centro Interdisciplinario de Estudios de Género de la Facultad de Ciencias Sociales de la Universidad de Chile. Actualmente es investigadora de la ONG Leasur. Su correo electrónico es javierafarias@leasur.cl.

Agustín Walker Martínez es estudiante de Derecho de la Universidad de Chile e investigador de la ONG Leasur. Su correo electrónico es agustinwalker@leasur.cl. 